\title{
Structural and Optical Properties of GaN Thin Films Grown on Si (111) by Pulsed Laser Deposition
}

\author{
Luis Arturo Martínez-Ara ${ }^{a}{ }^{\oplus}$, Jorge Ricardo Aguilar-Hernández ${ }^{a}{ }^{\circledR}$, Jorge Sastré-Hernández $z^{b}$, \\ Luis Alberto Hernández-Hernández $z^{a, c}$, María de los Ángeles Hernández-Pérez', \\ Patricia Maldonado-Altamirano ${ }^{e}$, Rogelio Mendoza-Pérez $z^{f}$,Gerardo Contreras-Puente ${ }^{a}$ \\ ${ }^{a}$ Escuela Superior de Física y Matemáticas, Instituto Politécnico Nacional, Edificio 9, U.P.A.L.M., San \\ Pedro Zacatenco, C.P. 07738, Ciudad de México, México \\ ${ }^{b}$ Tecnológico de Monterrey, Escuela de Ingeniería y Ciencias, Av. Carlos Lazo No. 100, Col. Santa Fe, \\ Álvaro Obregón, C.P. 01389, Ciudad de México, México \\ 'Escuela Superior de Apan, Universidad Autónoma del Estado de Hidalgo, Carretera Apan-Calpulalpan \\ km. 8, C.P. 43900, Apan, Hidalgo, México \\ ${ }^{d}$ Instituto Politécnico Nacional, Departamento de Ingeniería en Metalurgia y Materiales, ESIQIE, \\ U.P.A.L.M., San Pedro Zacatenco, C.P. 07730, Ciudad de México, México \\ ${ }^{e}$ Centro de Investigación y de Estudios Avanzados del Instituto Politécnico Nacional, Av. IPN 2508, \\ Zacatenco, C.P. 07360, Ciudad de México, México \\ ${ }^{f}$ Universidad Autónoma de la Ciudad de México, Av. Prolongación San Isidro 151, Col. San Lorenzo \\ Tezonco, C.P. 09790, Ciudad de México, México
}

Received: April 10, 2018; Revised: November 20, 2018; Accepted: December 04, 2018

In this work we present results and analysis concerning the processing and characterization of Gallium Nitride (GaN) thin films (TF) grown on $\mathrm{Si}(111)$ substrates by pulsed laser deposition technique (PLD), which were analyzed by X-ray diffraction (XRD), scanning electron microscopy (SEM), photoluminescence (PL) and Raman spectroscopy (RS). The GaN films showed the hexagonal phase with a preferential orientation in the (100) direction, SEM pictures showed a cauliflower-like morphology. Room temperature PL studies showed the so called GaN-yellow band, at $2.29 \mathrm{eV}$, as well as the donor-acceptor (DA) pair luminescent transition around $3.0 \mathrm{eV}$. At $10 \mathrm{~K}$, phonon replicas, separated by $69 \mathrm{meV}$, were observed. By RS, the optical mode on $710 \mathrm{~cm}^{-1}$ was observed, corresponding to the longitudinal optical phonon, $\mathrm{A}_{1}(\mathrm{LO})$, as reported for this material.

Keywords: Gallium nitride, Pulsed Laser Deposition, Photoluminescence.

\section{Introduction}

The nitride semiconductors, particularly GaN, have useful applications as light-emitting devices and as robust semiconductors for possible uses in transparent microelectronics ${ }^{1}$. Most of the best quality thin films are produced by molecular beam epitaxy (MBE) or metalorganic chemical vapour deposition (MOCVD), thus the exploration of fast and not so expensive techniques, like sublimation ${ }^{2}$ or $\mathrm{PLD}^{3-6}$, that makes possible to obtain good quality materials, results of interest for the materials science community. With PLD technique is possible to grow thin films into high vacuum level, at low substrate temperatures and at fast growth rate of the order of $\AA /$ pulse, to obtain stoichiometric films. The plasma formation ejected with the PLD-plume dissociates the $\mathrm{N}_{2}$-molecules from a nitrogen atmosphere and in this way having highly reactive atomic $\mathrm{N}$ radicals. Some results concerning the growth of GaN films by PLD were reported by Vinegoni et $\mathrm{al}^{4}$. They got films with small homogeneously distributed granular structures

*email: mtzara1984@gmail.com over the entire sample surface. Moreover high crystalline quality epitaxial have been processed by Vispute et $\mathrm{al}^{5}$. on $\mathrm{Al}_{2} \mathrm{O}_{3}(0001)$ substrate.

$\mathrm{GaN}$ crystallizes in the hexagonal or wurtzite $(\alpha)$ phase is the more stable one, whereas the zincblende structure is the metastable ( $\beta$ ) phase ${ }^{7}$. In order to avoid delamination of thin films grown by PLD, it is usually required to have a good crystalline lattice match between the substrate and the GaN film, and simultaneously proper growth conditions, mainly high temperature $\left(700-850^{\circ} \mathrm{C}\right)$ of the substrate. The most employed substrate is sapphire with the (0001) direction ${ }^{8,9}$, however silicon also represents an alternative as substrate, because it has advantages over sapphire, like cost, high thermal conductivity, large area substrates, among others ${ }^{10,11}$.

\section{Experimental}

Monocrystalline $\mathrm{Si}$ wafers $\left(1 \mathrm{~cm}^{2}\right)$, with (111) orientation, were used as substrates, they were cleaned with hydrofluoric acid (HF) at $100 \%$ concentration for few seconds and dry with $\mathrm{N}_{2}$ gas. The chemical treated substrates were immediately 
introduced into the PLD-growth chamber. For the PLD process a circular target (one-inch diameter and $3 \mathrm{~mm}$ thick) of $\mathrm{GaN}$ was used, which was obtained by compressing high purity powder (Aldrich) $99.99 \%$ at $1 \mathrm{Kbar}$. ANd-YAG laser with $1064 \mathrm{~nm}$ wavelength, $12 \mathrm{~ns}$ pulse duration, a power of $2.8 \mathrm{~W}$ and a repetition rate of $50 \mathrm{~Hz}$, was used for the ablation process. The substrate temperature was kept at 850 ${ }^{\circ} \mathrm{C}$ during the PLD process and the growth chamber was feeded with $\mathrm{N}_{2}$ gas flow of $40 \mathrm{sccm}$, reaching a pressure of $10^{-1}$ Torr during the growth process of the films. The deposition time was fixed at 20 minutes, in order to obtain films $150 \mathrm{~nm}$ in thickness.

The optical characterization was carried out in a conventional PL-set up from $10 \mathrm{~K}$ to room temperature (RT). For PL measurements a He-Cd laser was used as exciting light, at $325 \mathrm{~nm}$, with a power of $40 \mathrm{~mW}$. Raman spectra were obtained by using a He-Ne laser $(633 \mathrm{~nm}, 30 \mathrm{~mW})$ in a LabRam HR Evolution equipment. The XRD diffraction patterns were measured in the grazing angle configuration with a Bruker Advance diffractometer, whereas micrographs were obtained with a JSM6300 scanning electronic microscope.

\section{Results and Discussion}

GaN film was polycrystalline in nature, as determined by XRD. Figure 1 shows the corresponding diffraction pattern, which covers from 28 to 40 degrees (in the $2 \theta$ axis), because in this region it is possible to clear up the diffraction signal from the background noise. Above $2 \theta=40^{\circ}$ we did not found any diffraction signal.

As it can be seen there are well defined diffraction peaks due to $\mathrm{GaN}$ film ${ }^{12}$, the peak at 31.7 is related to the (100) plane, whereas the peak at 34.4 corresponds to the (002) plane, while the peak at 36.2 is associated to the (101) plane; all of them are related to the wurtzite crystalline structure according to PDF 01-073-7289 card. The intensity of each one of the $\mathrm{GaN}$ diffraction peaks were compared to the respective intensities of the peaks, as reported in the PDF card. According to this comparison, it is possible to assert

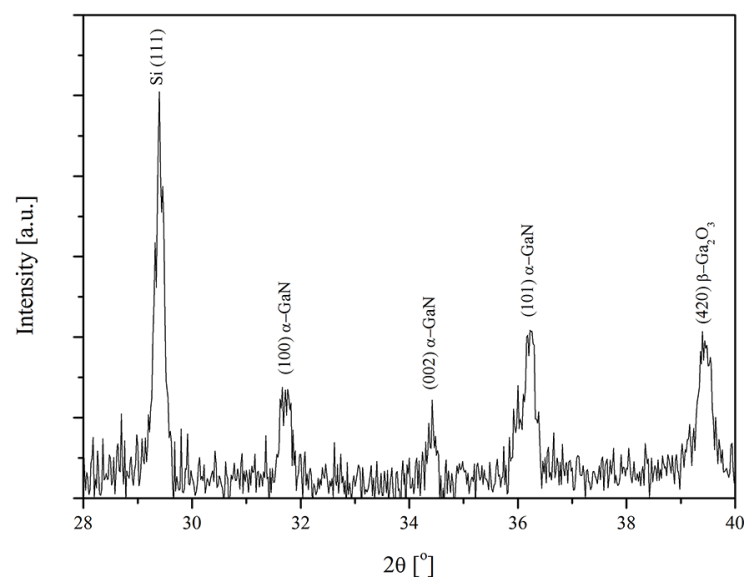

Figure 1. XRD pattern of the GaN film grown on (111) Si substrate. that the preferential orientation corresponds to the (100) plane. On the other hand, the peak at 39.4 is related to the (420) orientation of the $\beta-\mathrm{Ga}_{2} \mathrm{O}_{3}$ phase, PDF 00-006-0529.

Taking into account the two more intense diffraction peaks, (101) and (100), crystallite sizes of 16 and $26 \mathrm{~nm}$ respectively, were calculate by using the Scherrer-equation.

The diffraction peaks undergo a small shift, lower than $2 \theta=0.7$, as compared to the theoretical values. This small shift could be due to tensile strain produced by the mismatch lattice between the film and substrate ${ }^{13}$. Just for matter of comparison, the strongest peak at 29.4 corresponding to the (111) crystalline orientation of the Si substrate, does not suffer any shift.

Figure 2 depicts a SEM-micrograph of the film surface, the image was taken at $100000 \mathrm{X}$, it was not possible to obtain an image at higher magnification because the sample got charged avoiding a further magnification. From the SEM image it can be noticed a cauliflower-like morphology, also porous surface showing an uncompleted surface coverage can be observed.

The room temperature PL spectra were taken at two different points, separated $0.5 \mathrm{~cm}$ from each other, on the surface of the same sample in order to verify the homogeneity of the PL emission. It is possible to observe three bands, the yellow luminescence (YL) band, centered at $2.25 \mathrm{eV}$, the blue emission luminescence (BL) at $2.82 \mathrm{eV}$ and the near band edge (NBE) emission, at $3.0 \mathrm{eV}$. In general, it is possible to see that the relative emission intensity of these bands is different at each point, so the PL spectra depends on laser spot position as it can be seen in Figure 3. It has been reported that the YL could be due to different radiative defects, different hypothesis about the so called GaN-yellow band have been proposed in order to explain its origin, one of the most accepted is due to transitions from shallow donors to deep acceptors ${ }^{14,15}$, on the other hand, some researchers have associated it to native defects, like Ga vacancies because of unintentionally impurities incorporated during the material growth process ${ }^{16,17}$. On the other side, the NBE emission,

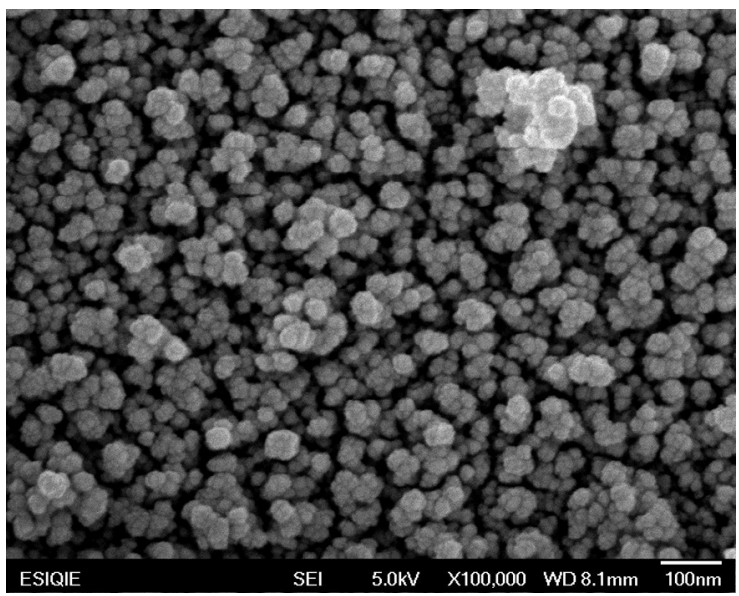

Figure 2. SEM image of $\mathrm{GaN}$ film grown on $\mathrm{Si}$ (111) substrate. 
it is usually associated to DA-pair luminescent transition according to Reshchikov et al. ${ }^{16,18,19}$. According to literature $\mathrm{BL}$ is related to $\beta-\mathrm{Ga}_{2} \mathrm{O}_{3}$ nanostructure ${ }^{20}$. This emission is originated from the recombination of an electron on a donor formed by oxygen vacancies and a hole on an acceptor formed by gallium vacancies ${ }^{21}$. The oxygen incorporation is due to target handling and high pressure during the growth process.

Taking into account this fact, we measure the PL emission, at both points on the sample surface, as a function of temperature. Both sets of spectra show the PL evolution in the range from 10 to $300 \mathrm{~K}$. As it can be seen, there is a dependence of the intensity and the position of the PL bands, as well as a quenching of the PL signal as expected ${ }^{22}$. Figure 4 shows the set of PL spectra obtained at the $1^{\text {st }}$ point. Variation of the shape and position of YL with temperature has been the topic of several publications ${ }^{14,16,23}$. When the temperature increases from $10-300 \mathrm{~K}$, the position of the YL band undergoes a small shift, around $40 \mathrm{meV}$, towards $2.29 \mathrm{eV}$, at $10 \mathrm{~K}$. The spectra depicted also the ultraviolet luminescence band (UVL), approximately at $3.37 \mathrm{eV}$, which quenches and completely vanishes at temperatures above $150 \mathrm{~K}$.

The high energy side of the PL spectrum, above $3.0 \mathrm{eV}$, of GaN film, at $10 \mathrm{~K}$, is shown in Figure 5. It can be seen additional PL structures located at 3.362, 3.293, 3.223,

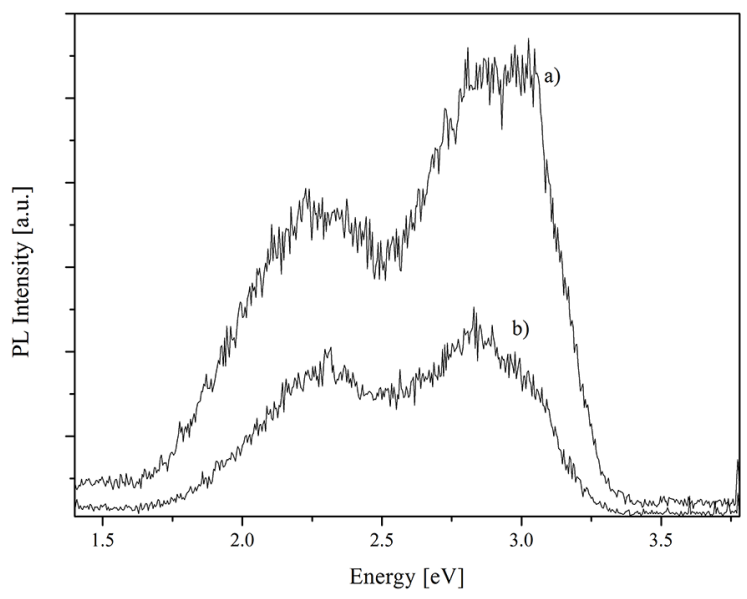

Figure 3. Room temperature PL spectra of a GaN film taken at two different points on the surface: a) $1^{\text {st }}$ point, b) $2^{\text {nd }}$ point.

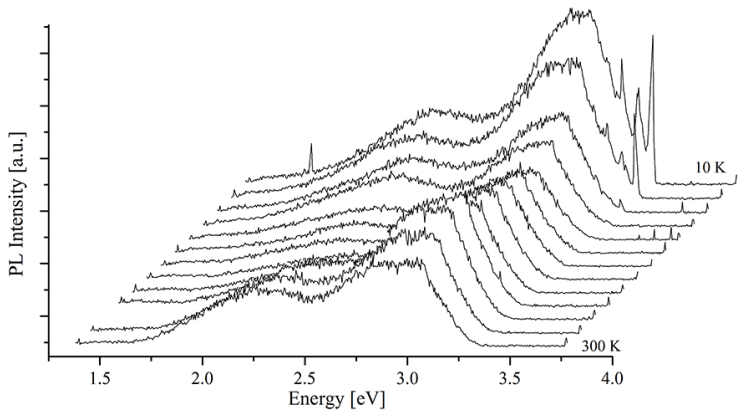

Figure 4. PL spectra as a function of temperature, 10 to $300 \mathrm{~K}$, for a GaN film taken at the $1^{\text {st }}$ point on the surface.
$3.154 \mathrm{eV}$, which are separated $69 \mathrm{meV}$ from each other, these three regular spaced structures account for the coupling of phonons to the PL emission at $3.362 \mathrm{eV}$, moreover the respective vibrational frequency corresponds to the transversal optical phonon (TO) designated as $\mathrm{E}_{1}$ with a frequency of $559 \mathrm{~cm}^{-124}$. This coupling of TO phonon, $\mathrm{E}_{1}$, in $\mathrm{GaN}$, has been also reported by $\mathrm{Z}$. Chen et $\mathrm{al}^{25}$, in $\mathrm{GaN}$ grown by MOCVD on $\mathrm{Al}_{2} \mathrm{O}_{3}$ substrates.

Figure 6 shows the temperature dependence of these PL structures, as it can be seen all the phonon replicas follow this trend in 10 to $150 \mathrm{~K}$ temperature range, with the largest energy shift being about $52 \mathrm{meV}$.

The set of PL spectra obtained at the second emission point of the GaN film are shown in the Figure 7. It is also possible to observe a dependence of the intensity, as well as the position, of the PL bands. At room temperature there are two signals, the first one correspond to YL around at 2.30 $\mathrm{eV}$, whereas the second one, due to DA-pair luminescent transition, is located at $3.05 \mathrm{eV}^{26}$. It is observed, that the

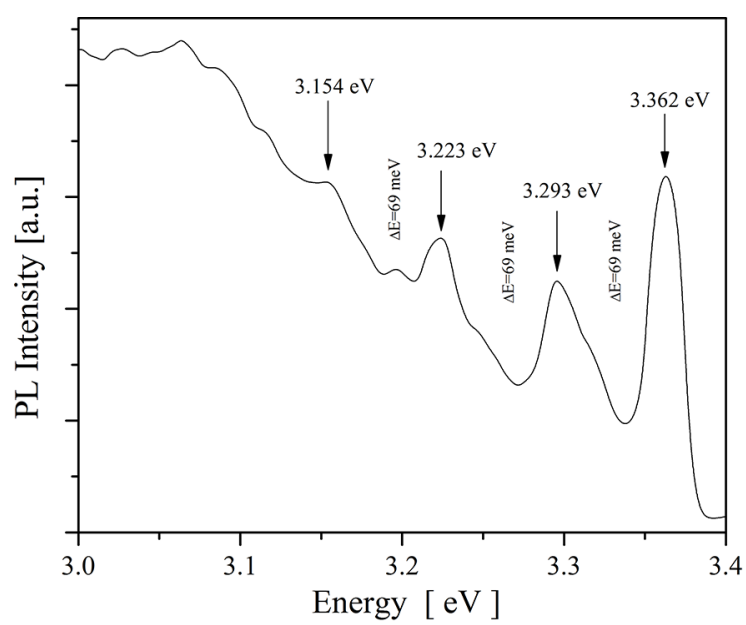

Figure 5. $10 \mathrm{~K}$ PL spectrum of a GaN film, showing the phonon replica.

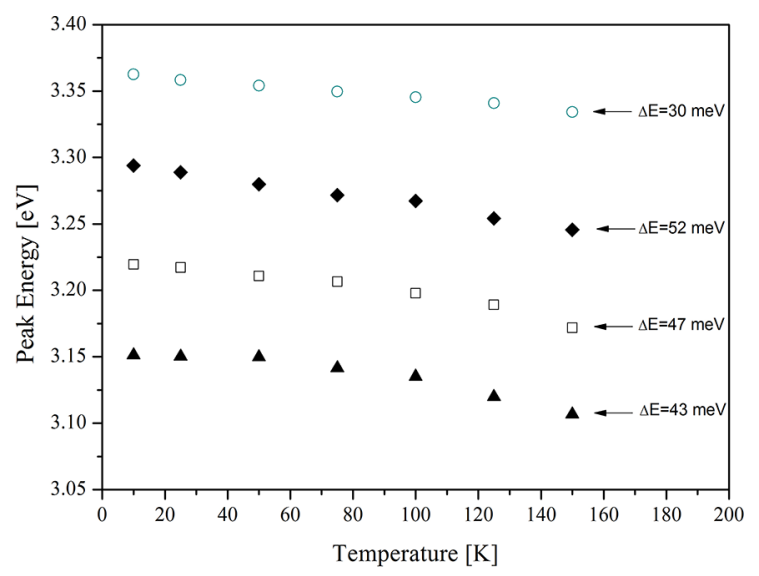

Figure 6. Position of the PL zero phonon line, ZPL, and phonon replica as a function of temperature for the $\mathrm{GaN}$ film, at the first focusing point. 
YL emission intensity is higher than the NBE emission at lowest temperature $(10 \mathrm{~K})$.

The PL spectrum at $10 \mathrm{~K}$, also presents the ultraviolet luminescence band (UVL) as shown in Figure 8. The phonon replica structures, at 3.349, 3.281, 3.21, $3.141 \mathrm{eV}$, are also separated by $69 \mathrm{meV}$, whereby we assume, as before, that they are due to coupling with TO phonon ${ }^{25}$.

The temperature dependence of the PL structures of the ultraviolet luminescence band (UVL) taken at the second point, is shown in Figure 9. It can be seen that the phonon replica structures follow a similar trend, as that of Figure 6. In this case all these structures vanish above $125 \mathrm{~K}$.

Phonon modes of GaN have received considerable attention due to that the information that these could provide is important in considering the electron transport, the nonradiative electron relaxation process, among others. However, the phonon frequencies of GaN wurtzite phase depend slightly of the growth process of the films. A Raman spectrum of the GaN sample grown on $\mathrm{Si}$ (111) is shown in Figure 10, it was recorded at room temperature. The peak centered at $710 \mathrm{~cm}^{-1}$ was multiplied by a factor 50 in order to get better

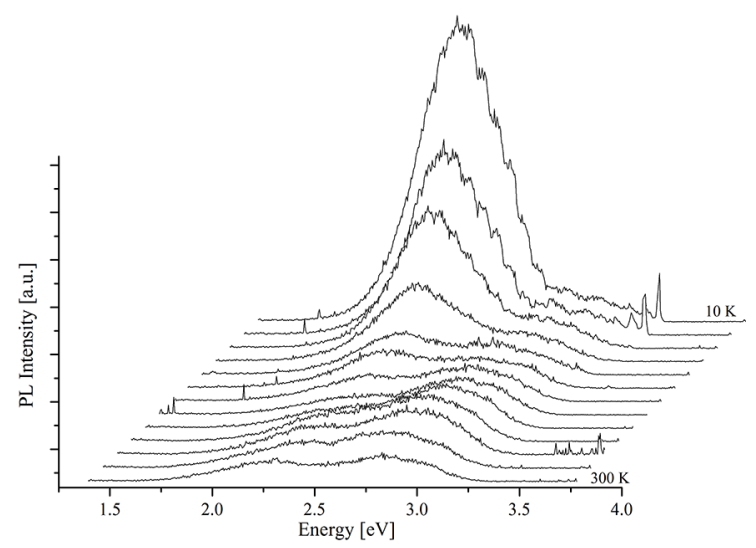

Figure 7. Temperature dependence of the PL spectra from 10 to $300 \mathrm{~K}$ for $\mathrm{GaN}$ film at the $2^{\text {nd }}$ point.

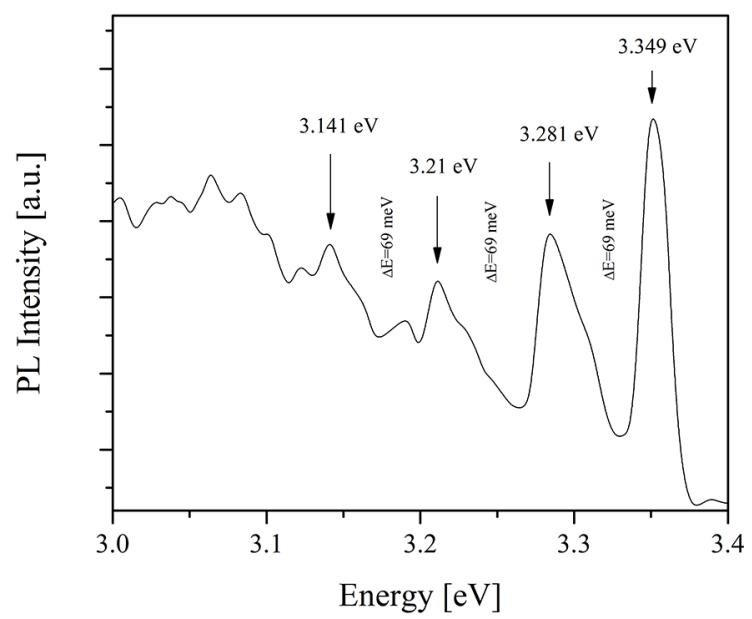

Figure 8. Low temperature (10 K) PL spectrum of GaN film in the UVL band at the $2^{\text {nd }}$ point.

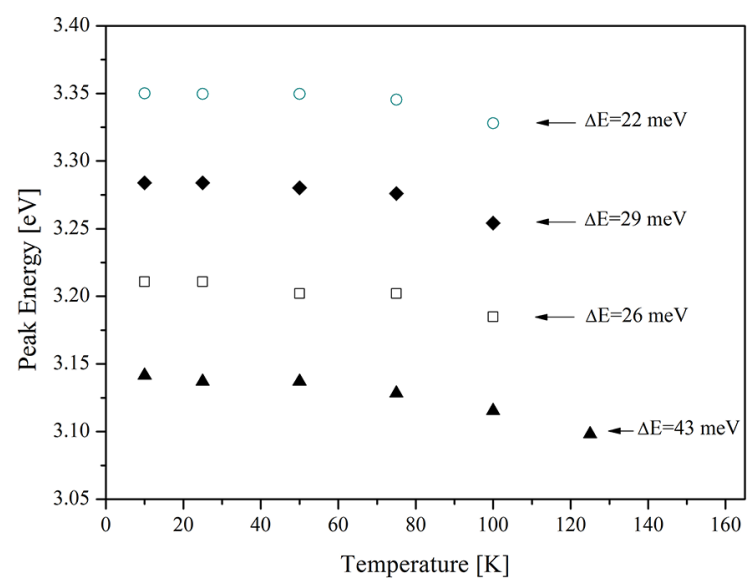

Figure 9. Position of the PL zero phonon line, ZPL, and phonon replica as a function of temperature for the GaN film, at the second focusing point.

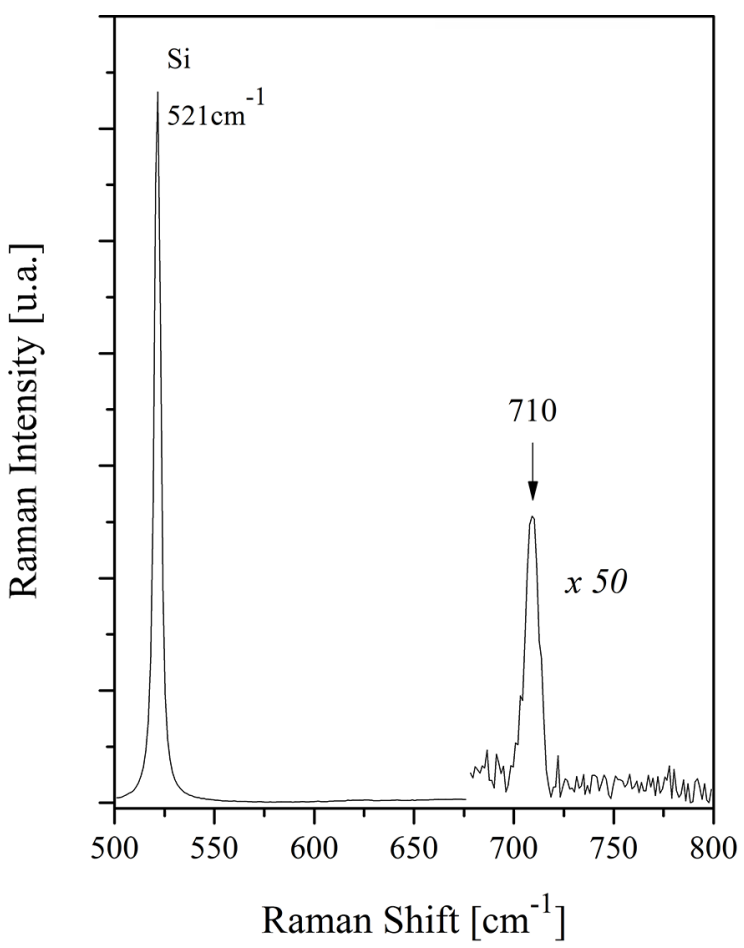

Figure 10. Raman spectra of GaN film grown on $\mathrm{Si}$ (111) substrate.

appreciation. This has been attributed to the longitudinal optical phonon of the $\mathrm{GaN}$ in wurtzite structure, $\mathrm{A}_{1}(\mathrm{LO})^{27,28}$. Some authors previously reported on Raman mode shifts in $\mathrm{GaN}$ with a frequency lower than $734 \mathrm{~cm}^{-1}$, the shift may arise from the presence of phonon confinement assuming the presence of nano-sized crystals suggesting a polycrystalline character of our films in accordance to $\mathrm{XRD}^{4}$ results. We discard that this phonon is related to $\beta-\mathrm{Ga}_{2} \mathrm{O}_{3}$, because the $\beta-\mathrm{Ga}_{2} \mathrm{O}_{3}$ Raman signal is presented at $767 \mathrm{~cm}^{-1}$ (29. 


\section{Conclusions}

We have processed and studied GaN films grown by PLD on Si (111) substrates, in a $\mathrm{N}_{2}$ atmosphere inside the PLD-chamber growth. The XRD pattern reveals the polycrystalline character of the films due to the presence of the (100), (002) and (101) directions related to wurtzite phase of GaN. A small contribution of Ga-oxide phase is confirmed due to the presence of the (420) crystallographic direction. According to the SEM micrographs nanometric cauliflowerlike structures are observed. PL signal depends on laser spot position on the surface of the sample, mainly the intensity of the NBE at $3.0 \mathrm{eV}$, as observed from the respective spectra. Temperature dependence of the PL signal was measured from 10 to $300 \mathrm{~K}$ at two different points on the same sample. At low temperature the PL spectra showed a high energy band at $3.36 \mathrm{eV}$, related to excitonic transition. At $10 \mathrm{~K}$, the UVL band shows structures separated by $69 \mathrm{meV}$ corresponds to the transversal optical phonon (TO) designated as $\mathrm{E}_{1}$ with a frequency of $559 \mathrm{~cm}^{-1}$. The Raman spectrum shows a peak centered at $710 \mathrm{~cm}^{-1}$, which is associated to $\mathrm{A}_{1}(\mathrm{LO})$ of $\mathrm{GaN}$ in wurtzite structure.

\section{Acknowledgements}

L.A.M.A acknowledges to Conacyt by Ph.D. scholarship. This work was supported by SIP-IPN, project numbers 20170216, 20170135, 2018335, 20180374.

\section{References}

1. Uang KM, Wang SJ, Chen SL, Wu CK, Chang SC, Chen TM, et al. High-Power GaN-Based Light-Emitting Diodes with Transparent Indium Zinc Oxide Films. Japanese Journal of Applied Physics. 2005;44(Pt 1):2516.

2. Santana-Rodríguez G, de Melo O, Aguilar-Hernández J, MendozaPérez R, Monroy BM, Escamilla-Esquivel A, et al. Photoluminescence Study of Gallium Nitride Thin Films Obtained by Infrared Close Space Vapor Transport. Materials (Basel). 2013;6(3):1050-1060.

3. Contreras-Puente G, Cantarero A, Recio JM, de Melo O, HernándezCruz E, de Moura Flores F, et al. Raman measurements on GaN thin films for PV-purposes. In: Proceedings of the 37th IEEEPhotovoltaic Specialists Conference; 2011 Jun 19-24; Seattle, WA, USA. p. $36-38$

4. Vinegoni C, Cazzanelli M, Trivelli A, Mariotto G, Castro J, Lunney JG, et al. Morphological and optical characterization of GaN prepared by pulsed laser deposition. Surface and Coatings Technology. 2000;124(2-3):272-277.

5. Vispute RD, Talyansky V, Sharma RP, Choopun S, Downes M, Venkatesan T, et al. Growth of epitaxial GaN films by pulsed laser deposition. Applied Physics Letters. 1997;71(1):102-104.

6. Yoshida T, Kakumoto S, Sugimura A, Umezu I. Synthesis of $\mathrm{GaN}$ nanocrystallites by pulsed laser ablation in pure nitrogen background gases. Applied Physics A. 2011;104(3):907-911.
7. Wang LD, Kwok HS. Cubic aluminum nitride and gallium nitride thin films prepared by pulsed laser deposition. Applied Surface Science. 2000;154-155:439-443.

8. Sudhir GS, Fujii H, Wong WS, Kisielowski C, Newman N, Dieker $\mathrm{C}$, et al. Pulsed laser deposition of aluminum nitride and gallium nitride thin films. Applied Surface Science. 1998;127-129:471-476.

9. Cazzanelli M, Cole D, Versluijs J, Donegan JF, Lunney JG. Pulsed laser deposition of $\mathrm{GaN}$ thin films. Materials Science and Engineering: B. 1999;59(1-3):98-103.

10. Hiroyama Y, Tamura M. Effect of Very Thin SiC Layer on Heteroepitaxial Growth of Cubic GaN on Si (001). Japanese Journal Applied Physics. 1998;37(Pt 2 6A):L630.

11. Cervantes-Contreras M, López-López M, Luyo-Alvarado J, Meléndez-Lira M, Tamura M. Estudio de películas de GaN crecidas por epitaxia de haces moleculares sobre substratos de $\mathrm{Si}$ en las direcciones (111) y (001) recubiertos con una capa delgada de SiC. Superficies y Vacio. 2000;10:48-50.

12. Xiao RF, Liao HB, Cue N, Sun XW, Kwok HS. Growth of c-axis oriented gallium nitride thin films on an amorphous substrate by the liquid-target pulsed laser deposition technique. Journal of Applied Physics. 1996;80(7):4226-4228.

13. Yam FK, Low LL, Oh SA, Hassan Z. Gallium Nitride: An Overview of Structural Defects, Optoelectronics-Materials and Techniques. In: Predeep P, ed. Optoeletronics. Rijeka: InTech; 2011.

14. Ogino T, Aoki M. Mechanism of Yellow Luminescence in GaN Japanese Journal of Applied Physics. 1980;19(12):2395.

15. Perry WG, Bremser MB, Davis RF. Cathodoluminescence studies of the deep level emission bands of AlxGa1-xN films deposited on 6H-SiC(0001). Journal of Applied Physics. 1998;83(1):469-475.

16. Reshchikov MA, Morkoç H. Luminescence properties of defects in GaN. Journal of Applied Physics. 2005;97(6):061301.

17. Polyakov AY, Shin M, Freitas JA, Skowronski M, Greve DW, Wilson RG. On the origin of electrically active defects in AlGaN alloys grown by organometallic vapor phase epitaxy. Journal of Applied Physics. 1996;80(11):6349-6354.

18. Middleton PG, O'Donnell KP, Trager-Cowan C, Cole D, Cazzanelli M, Lunney J. The emission spectrum of pulsed laser deposited GaN and its powder precursor. Materials Science and Engineering: $B$. 1999;59(1-3):133-136.

19. Huang TF, Marshall A, Spruytte S, Harris JS Jr. Optical and structural properties of epitaxial GaN films grown by pulsed laser deposition. Journal of Crystal Growth. 1999;200(3-4):362-367.

20. Xiang X, Cao CB, Zhu HS. Synthesis and photoluminescence of gallium oxide ultra-long nanowires and thin nanosheets. Journal of Crystal Growth. 2005;279(1-2):122-128.

21. Chun HJ, Choi YS, Bae SY, Seo HW, Hong SJ, Park JG, et al. Controlled Structure of Gallium Oxide Nanowires. Journal of Physical Chemistry B. 2003;107(34):9042-9046.

22. Sanguino P, Niehus M, Melo LV, Schwarz R, Koynov S, Monteiro $\mathrm{T}$, et al. Characterisation of GaN films grown on sapphire by low-temperature cyclic pulsed laser deposition/nitrogen $\mathrm{rf}$ plasma. Solid-State Electronics. 2003;47(3):559-563.

23. Zhang R, Kuech TF. Photoluminescence of carbon in situ doped $\mathrm{GaN}$ grown by halide vapor phase epitaxy. Applied Physics Letters. 1998;72(13):1611-1613. 
24. Kuball M. Raman spectroscopy of GaN, AlGaN and AlN for process and growth monitoring/control. Surface and Interface Analysis. 2001;31(10):987-999.

25. Chen Z, Lu DC, Liu X, Wang X, Han P, Wang D, et al. Luminescence study of (1120) GaN film grown by metalorganic chemical-vapor deposition. Journal of Applied Physics. 2003;93(1):316-319.

26. Reshchikov MA. Evaluation of GaN by photoluminescence measurement. Physica Status Solidi C. 2011;8(7-8):2136-2138.
27. Azuhata T, Sota T, Suzuki K, Nakamura S. Polarized Raman spectra in GaN. Journal of Physics: Condensed Matter. 1995;7(10):L129.

28. Cingolani A, Ferrara M, Lugarà M, Scamarcio G. First order Raman scattering in GaN. Solid State Communications. 1986;58(11):823-824.

29. Zhao Y, Frost RL. Raman spectroscopy and characterization of a-gallium oxyhydroxide and ß-gallium oxide nanorods. Journal of Raman Spectroscopy. 2008;39(10):1494-1501. 